\title{
Smoke-free spaces: a decade of progress, a need for more?
}

\author{
Sean Semple (1) , ${ }^{1}$ Ruaraidh Dobson, ${ }^{1}$ Rachel O'Donnell, ${ }^{1}$ Emilia Zainal Abidin, ${ }^{2}$ \\ Olena Tigova, ${ }^{3,4,5,6}$ Gabriel Okello, ${ }^{7,8,9}$ Esteve Fernández (1) 3,4,5,6
}

${ }^{1}$ Institute of Social Marketing and Health, University of Stirling, Stirling, UK

${ }^{2}$ Department of Environmental and Occupational Health, Faculty of Medicine and Health Sciences, Universiti Putra Malaysia, Serdang, Selangor, Malaysia

${ }^{3}$ Tobacco Control Unit, Catalan Institute of Oncology - ICO, WHO Collaborating Centre for Tobacco Control, Catalan Institute of Oncology, L'Hospitalet de Llobregat, Barcelona, Spain

${ }^{4}$ Tobacco Control Research Group, Bellvitge Biomedical Research Institute - IDIBELL, L'Hospitalet de Llobregat, Barcelona, Spain

${ }^{5}$ School of Medicine and Health Sciences, University of Barcelona, Barcelona, Spain ${ }^{6}$ Centro de Investigación Biomédica en Red de Enfermedades Respiratorias (CIBERES), Madrid, Spain

${ }^{7}$ African Centre for Clean Air, Kampala, Uganda

${ }^{8}$ Cambridge Institute for Sustainability Leadership, University of Cambridge, Cambridge, UK

${ }^{9}$ AirQo, College of Computing and Information Sciences, Makerere University, Kampala, Uganda

\section{Correspondence to}

Dr Sean Semple, Institute of Social Marketing, University of Stirling, Stirling FK9 4LA, UK; sean.semple@stir.ac.uk

Received 14 June 2021 Accepted 3 November 2021

\section{Check for updates}

(C) Author(s) (or their employer(s)) 2022. No commercial re-use. See rights and permissions. Published by BMJ.

To cite: Semple $S$, Dobson $R$, O'Donnell R, et al. Tob Control

2022;31:250-256.

\section{ABSTRACT}

Adoption of smoke-free measures has been one of the central elements of tobacco control activity over the past 30 years. The past decade has seen an increasing number of countries and proportion of the global population covered by smoke-free policies to some extent. Despite reductions in global smoking prevalence, population growth means that the number of non-smokers exposed to the harms caused by secondhand smoke remains high. Smoke-free policy measures have been shown to be useful in protecting non-smokers from secondhand smoke, and can additionally increase cessation and reduce smoking initiation. Policies tend to be aimed primarily at enclosed public or workplace settings with very few countries attempting to control exposure in private or semiprivate spaces such as homes and cars, and, as a result, children may be benefiting less from smoke-free measures than adults. Compliance with legislation also varies by country and there is a need for education and empowerment together with guidance and changing social norms to help deliver the full benefits that smoke-free spaces can bring. Restrictions and policies on use of electronic cigarettes (e-cigarettes) in smoke-free settings require more research to determine the benefits and implications of bystanders' exposure to secondhand e-cigarette aerosol, dual use and smoking cessation.

\section{INTRODUCTION}

An important part of the 30-year history of this journal centres on publishing research dedicated to understanding how best to protect non-smokers from the harms posed by breathing secondhand tobacco smoke (SHS) or environmental tobacco smoke, as it was commonly referred to during 1990s and early 2000s. A quick search of the journal website for the term 'smoke-free' returns over 1700 articles with 145 of these using the phrase in the title. The research has been important, varied and cross-disciplinary: from examining the impacts of smoke-free policies on mortality ${ }^{1}$ and hospital admissions, ${ }^{2}$ through to the macro-economics of cities $^{3}$ and levels of betting at individual venues. ${ }^{4}$ Work has also covered a wide range of settings from hospitals ${ }^{5}$ and homes, ${ }^{6}$ to airports, ${ }^{7}$ pagodas, ${ }^{8}$ parks and beaches. ${ }^{9}$ The journal has built on epidemiological work that has identified links between inhaling SHS and increased risk of disease ${ }^{10}$ and developmental problems in children including low birth weight, ${ }^{11}$ reduced lung function ${ }^{12}$ and exacerbation of asthma. ${ }^{13}$ These findings have led to or supported important developments in delivery, policy and practice; helped define or evaluate a specific section (Article 8) of the WHO Framework Convention on Tobacco Control (FCTC) in $2003^{14}$; and the consequent MPOWER policy strategy approach published in 2009. ${ }^{15}$

In tandem with the increasing recognition of the need to better understand the health effects of SHS, there have also been significant advances in scientific methods of measuring and quantifying exposure to SHS. Simple metrics or proxies of exposure such as living with a smoker or working in a smoking-permitted workplace have progressed to methods involving real-time measurements of tobacco-generated concentrations of fine particulate matter $\left(\mathrm{PM}_{2.5}\right),{ }^{16}$ nicotine in air ${ }^{17}$ or biomarkers of nicotine intake ${ }^{18}$ including salivary cotinine. Interest in more refined and lower cost exposure assessment techniques has increased as part of evaluations of policies to reduce SHS, with the tobacco control community embracing methods from both air pollution science ${ }^{19}$ and industrial hygiene disciplines where expertise in aerosol measurement has an even longer history. ${ }^{20}$

The use of electronic cigarettes (e-cigarettes) has also become increasingly common as smokers look for ways to stop smoking and/or to consume nicotine in settings where smoking is no longer permitted. Public health experts continue to debate the effects of secondhand e-cigarette aerosols (SHAs) on bystanders, the need to control e-cigarette use and whether policy restrictions to limit exposure to SHA are required. ${ }^{21} 22$ Measurement of SHA is complex and the methods used to quantify bystander exposure are currently poorly developed. ${ }^{23}$ Policies on e-cigarette use are much more fragmented reflecting the tobacco control community's mixed views on the benefits of using e-cigarettes to tackle the tobacco epidemic versus the potential harms of a new generation of nicotine users, dual use and the impact of SHA exposure. ${ }^{24} 25$

Reductions in global smoking prevalence figures ${ }^{26}$ and smoke-free policies becoming more commonly adopted have meant that the age-standardised risk of being exposed to SHS has reduced by about $20 \%$ between 1990 and 2016. ${ }^{27}$ However, most recent figures indicate that about $19 \%$ of men and $33 \%$ of women worldwide continue to be exposed to SHS. ${ }^{27}$ Taking into account global population growth and increasing proportion of smokers in low/middleincome countries (LMICs) (which now account for $80 \%$ of smokers), there are now about 150 million more people who smoke than there were in 1990: an estimated 1.14 billion smokers on the planet in $2019 .^{26}$ It is thus likely that more people than ever are impacted by exposure to SHS with an estimated 
800000 premature deaths per year as a result of non-smokers' exposure to $\mathrm{SHS}^{28}$ Estimates suggest the number of nonsmokers exposed to SHS is between 1.5 and 1.9 billion-with evidence suggesting that 508 million children under 15 years were exposed to SHS at home across just 21 countries studied in $2015 .^{29}$ This is despite the fact that 180 countries are parties to the WHO FCTC, with moderate or complete smoke-free policies in accordance with Article 8 of the WHO FCTC now implemented in 96 countries.

There is also strong evidence that protection from SHS is unequal by income, gender, age and country, and contributes significantly to global health inequality. ${ }^{30}$ Those living in affluent areas of high-income countries are much less likely to experience exposure to SHS than poorer populations in LMICs. Women are much more likely to live with a smoker compared with men $^{28}$ : this is particularly true across many LMICs where gender differences in smoking prevalence are significant. Even in high-income countries, there is evidence (presented later in this paper) that non-smoking adults are better protected from SHS than children.

This commentary builds on an extended review published in $2011,{ }^{31}$ considers changes in the past decade and reflects on the current state of smoke-free policies globally, before examining how smoke-free policies are developing with reference to e-cigarettes and vaping, and how we can expect the policy landscape to change as we progress towards the tobacco endgame.

\section{Smoke-free policies globally}

Hyland and colleagues provide a detailed review of the development of smoke-free policies in their 2011 review. ${ }^{31}$ Smoking restrictions began to be introduced in a piece-meal fashion in high-income countries during the 1970s and 1980s, with 'no-smoking' areas of restaurants or 'no smoking' seats in particular sections of public transport. While many of these measures may have provided non-smokers with the option of not sitting directly next to someone who was smoking, they did little or nothing to reduce exposure to SHS and could certainly not be classified as 'smoke-free' policies. The US Surgeon General reports and increasing evidence of harm from SHS built momentum through the late 1980 s to early $2000 s^{32} 33$ with California implementing smoke-free bars and restaurants in $1998 .^{34}$ Ireland is credited with implementing the first comprehensive national smoke-free measures protecting non-smokers from SHS in enclosed public spaces in 2004. This bold measure included prohibiting smoking in pubs and bars, and was influential in setting the direction of travel for many other European countries to follow suit. Smoke-free policies and restrictions in many states in the USA, Australia and New Zealand are broadly similar and protect many people at work, on public transport and in leisure settings including bars, restaurants and nightclubs.

Smoke-free laws have been shown to have immediate and sustained positive health benefits in many of the jurisdictions where they have been applied: for example, a pooled analysis from 31 global studies suggests about a $12 \%$ reduction in cardiovascular events immediately following smoke-free legislation. ${ }^{35}$ Analysis extending to 10 years post-legislation in Scotland suggests these effects are sustained for at least some parts of the population. $^{36}$

The approval and adoption of the WHO FCTC has led to a significant shift in the consensus about how to protect nonsmokers from SHS over the past 15 years. Prior to adoption, there tended to be debate about how voluntary measures could be a sufficient framework for protection. However, once the guidelines to Article 8 of the WHO FCTC outlining governmental duty and responsibility to provide protection were approved in 2007, the concept of relying on voluntary restrictions for workplace and public places became mute in policy discussions in most countries. This was a turning point in the adoption of smoke-free policies and now an estimated 1.8 billion people live in countries where comprehensive smokefree policies are enshrined in law. ${ }^{37}$ The type of settings covered, exemptions and the level of compliance and/or enforcement vary considerably by country. The most recent WHO Report on the Global Tobacco Epidemic (2021) ${ }^{37}$ indicates that 67 countries are classified as having 'complete' smoke-free policies (defined as all public places completely smoke-free-or at least $90 \%$ of the population covered by complete subnational legislation), 29 with moderate restrictions covering 6-7 types of public places, 43 with minimal policies in a small number of settings, and some 56 countries with either weak or no smoke-free policies or not reporting any data. The proportions of countries in each classification are broadly similar across high-income, middle-income and low-income nation categories: a significant change in the past decade with LMICs catching up with high-income countries in being equally likely to have laws to protect their populations from SHS. Research has examined country-level factors that influence implementation of tobacco control policies, with results suggesting that strong and transparent governance is key to ensuring that effective tobacco control policies are implemented. ${ }^{38}$ A recent ecological study assessed the association between country-level socioeconomic status and the implementation level of tobacco control policies in 31 European countries and found no association between socioeconomic status factors and the level of implementation of tobacco control policies indicating that, despite socioeconomic differences at country level, tobacco control policies can be successfully implemented, at least among high and upper middle-income countries. ${ }^{39}$

While it is an incredible achievement that comprehensive protection from SHS has increased from just 10 countries with a population of 0.2 billion in 2007 to cover 1.8 billion people or $23 \%$ of the global population in $2020,{ }^{37}$ the fact that over three in four people on the planet are likely to be exposed to SHS at some stage in their daily working, travel or leisure activity clearly presents the tobacco control community with a significant and continuing challenge.

However, figures on workplace and enclosed public space smoke-free legislation and policies tell only part of the story in relation to SHS exposure. Three other important factors should be considered: compliance with legislation; exposure in outdoor spaces and exposure in private settings (homes and cars).

Compliance varies markedly, the 2019 WHO report provides details of local assessors rating overall compliance across various types of public spaces (on a score of $0-10$ ) and indicated only 24 countries (eg, UK, Uruguay, Norway, Canada and New Zealand) achieved high levels of compliance at 9-10 on the scale. In contrast, low levels of compliance (rating 0-3) was identified in 32 countries. ${ }^{40}$ These included Vietnam, Pakistan, Egypt, Bolivia and Chad. These data call into question the idea that smokefree laws tend to be self-enforcing in countries with smokefree laws of similar strength: such a notion may have arisen from early adoption in high-income countries with decreasing smoking prevalence and a long history in tobacco control. This evidence indicates that comprehensive smoke-free laws may face enforcement challenges resulting in suboptimal compliance in particular venues of some countries. Increasing use of e-cigarettes and heated tobacco products (HTPs) may also undermine compliance even after the establishment of robust legislation as reported in a study in Guatemala. ${ }^{41}$ Understanding how to 
improve compliance in these settings represents a research challenge for the tobacco control community.

While there is some evidence that the existence of laws and regulations does not always transfer across to behaviour change and actual protection from SHS, ${ }^{38}$ there are also studies using the Tobacco Control Scale (which includes smoke-free measures) that demonstrate links to voluntary home smoking bans ${ }^{42}$ and cessation. ${ }^{43}$ Suboptimal compliance in countries that have enacted national smoke-free measures is a concern: simply passing legislation is not enough. ${ }^{44}$ Governments need to establish coordinated education and enforcement systems with welldefined and simple regulations to facilitate compliance.

Outdoor settings such as parks and beaches, and semienclosed outdoor settings like bar terraces are another part of understanding population exposure to SHS. ${ }^{45}$ The 2011 review by Hyland and colleagues ${ }^{31}$ observed an expansion of smoke-free policies to cover outdoor eating and drinking areas of bars or restaurants and entryways to buildings. This tendency is now consolidated and the tobaccocontrollaws.org database reports that smoke-free legislation for some outdoor workplaces and public places is in place in 86 countries. ${ }^{46}$ The precise definition of these open or semiopen spaces has become a key enforcement issue of smoke-free laws in these places because of the difficulties in interpreting and implementing the law around smoking in such outdoor areas. ${ }^{47}$ Nicotine and $\mathrm{PM}_{2.5}$ concentrations in these settings ${ }^{48}$ are usually significantly lower than in indoor settings due to air movement and dilution, and there are potentially major differences globally: walking past a smoker on a windswept Scottish beach may lead to considerably lower exposure when compared with sitting next to a group of smokers on a terrace outside on a still, warm evening in a Mediterranean country.

As exposure to SHS in public spaces has declined, emphasis or attention has shifted towards private spaces where smoking still occurs, such as homes and cars. The use of policy levers to reduce smoking in these environments has become a central goal of public policy in the past decade.

\section{Improvements for many but are we leaving particular groups behind?}

While the WHO FCTC Article 8 focuses on protecting nonsmokers from SHS at work and in public spaces, it does not call for restrictions in the private setting of the home or the highly regulated semiprivate environment found inside cars. It is in these spaces that family members, particularly children, are most commonly exposed to SHS generated by the smokers they live with. ${ }^{49}$ The small volume and poor ventilation rates in such environments can lead to concentrations of SHS that can be many times higher ${ }^{50}$ than have been measured in bars or workplaces. Some countries have moved to implement smoke-free cars, particularly those carrying children, but no country has proposed comprehensive measures to restrict smoking in the home beyond some measures around multi-unit, government-funded housing in the $\mathrm{USA}^{51}$ or restrictions on balcony smoking applied by some housing associations and landlords. As a result, children, who spend a greater proportion of their day at home compared with a working adult, are likely to have been left behind in terms of the protection offered by WHO FCTC Article 8 and MPOWER.

Figure 1 provides a previously unpublished comparison of the proportion of non-smoking adults and children in the UK who show detectable salivary cotinine (a marker of SHS exposure) between 1998 and 2016. While adults have benefited most by becoming nearly seven times less likely to be exposed to SHS

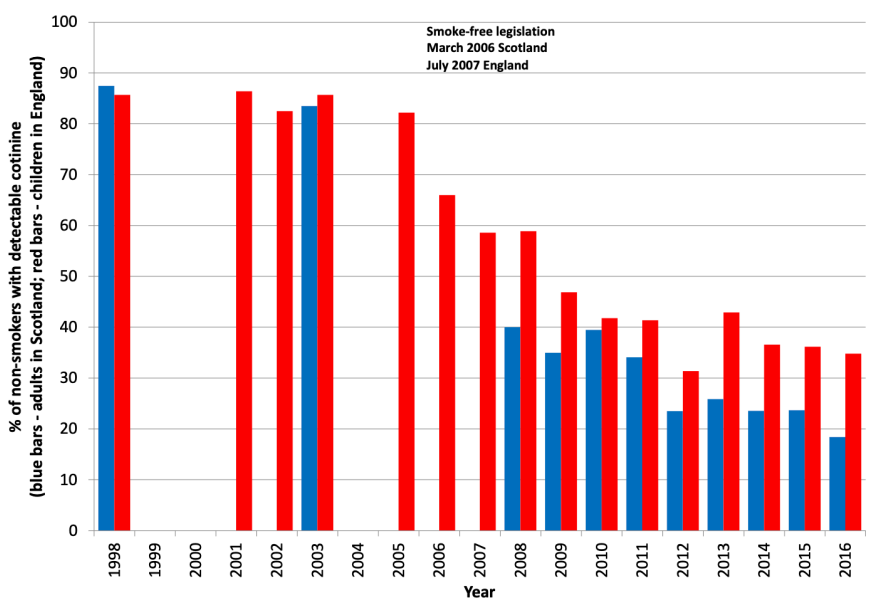

Figure 1 Proportion of children (age $<16)$ and adult $(16+)$ nonsmokers with detectable cotinine (data taken from the Scottish Health Survey and the Health Survey of England between 1998 and 2016).

with $19 \%$ having detectable cotinine by 2016 , the protection afforded to children by smoke-free laws in the UK has seen a smaller improvement, and by 2018 there are still nearly onethird of children with detectable levels of salivary cotinine indicating SHS exposure. On a global scale, it is important to note that large numbers of children continue to be exposed to SHS with estimates of 430 million children exposed to SHS across China, India, Bangladesh, Indonesia and the Philippines ${ }^{29}$ where male smoking prevalence is high and smoke-free homes are uncommon.

\section{Private and semiprivate spaces}

The past decade has seen moves to legislate to restrict smoking in private cars. A small number of countries and subnational states or regions have introduced mandatory restrictions including in Scotland, England, Italy, France and New Zealand, with varying regulations by different states in parts of the USA, Australia and Canada. These measures have been based on data showing air quality can deteriorate markedly when smoking takes place during a car journey with peaks in concentrations of $\mathrm{PM}_{2.5}$ reaching values that are often worse than those found in work spaces when smoking was permitted. ${ }^{52}$ The smoke-free focus in cars is on protecting children (and in Italy, pregnant women) from SHS, with the defined upper age of the child varying by country from 12 to 18 years. Recent analysis from England, Scotland and Wales suggests a 22\% reduction in the proportion of children reporting exposure to SHS in vehicles as a result of implementation of smoke-free cars legislation enacted in $2015 / 2016$. $^{53}$

One of the primary gaps in scientific understanding of the impacts of SHS is our imperfect knowledge of who smokes, when and where. To tackle exposure to SHS and to target and enforce smoke-free policies effectively, we need to know the 'when', 'where', 'why' and 'how' people are exposed. ${ }^{54}$ Timing and place of smoking are likely to be important in generating exposure: a parent who smokes in the living room while the children are asleep at home may be causing greater health harm than the same parent who chooses to smoke the same cigarette on the walk from work to home. Messages around timing of smoking are further complicated by the evidence that SHS can remain in the air for many hours after a cigarette is smoked and also leads to tobacco smoke deposition on home surfaces generating exposure to 'third-hand smoke'. ${ }^{55}$ So having a quick smoke indoors 
before the children come back from school is not an effective harm reduction solution.

While many workplaces no longer permit smoking globally, there are exceptions. Until recently in the UK prisons were one of the small number of workplaces where workers were exposed to SHS during the course of their daily activity, due to prisoners' cells being considered a home setting and thus falling outside smoke-free regulations. This has now changed, partly due to measurement activity demonstrating staff exposure to SHS. ${ }^{56}$ However, workers who have roles that involve outdoor tasks within hospitality settings ${ }^{57}$ or those involved in entering other people's home are likely to continue to experience exposure to SHS. A job-exposure matrix for the UK population concluded that over 1 million workers are likely to experience non-negligible exposure to SHS in terms of concentration and frequency of contact. ${ }^{58}$ The COVID-19-induced shift to 'home working' for many knowledge sector workers raises important questions about how employers protect their workforce from other people's smoke when they do not have control of the workspace where they carry out their work. Related to this, the COVID-19 pandemic has led to various types of lockdowns in various countries, necessitating the need to 'stay home'. This has led to children and adults spending more time in homes with the potential for increases in SHS exposure particularly in families from low-income households due to smaller living spaces and less access to private outdoor space such as gardens. ${ }^{5960}$ Even pre-COVID-19, there was evidence that children living in flats tend to have higher cotinine levels than those in detached houses, perhaps from SHS ingress through walls and shared ventilation systems. $^{61}$

Smoke-free policies have generally been considered to be effective levers in reducing health inequalities. In countries in the later stages of the tobacco epidemic, exposure to SHS is more common in areas of socioeconomic deprivation. Data show that workers in poorer paid jobs are more likely to be exposed to SHS, ${ }^{62}$ and similarly children living in poorer communities or poorer households are more likely to live with at least one smoking parent. ${ }^{63}$ This perpetuates a cycle of inequality, with poorer children suffering more lower respiratory infections, asthma attacks and episodes of otitis media as well as more serious acute diseases such as meningitis or sudden infant death syndrome. ${ }^{33}$ These poor health outcomes continue throughout the life course and even beyond it-children who grow up exposed to smoking in the home are more likely to become smokers themselves, ${ }^{64}$ potentially repeating the cycle with the next generation. Smoke-free policies, particularly those targeted to reduce children's exposure to SHS, can break this cycle and improve health equity across a population.

\section{What do smoke-free policies aim to achieve?}

It is worth considering what smoke-free policies may also achieve beyond the primary aim of protecting non-smokers from SHS within that setting. They undoubtedly change social norms around smoking-making it less acceptable to smoke and reducing the visibility of smoking. Calls for smoke-free policies in children's parks and outside schools may thus be less to do with exposure to SHS and more to prevent children from seeing smoking adults and modelling their smoking behaviour. ${ }^{65}$ Certainly, this is the argument for such measures highlighted in the 2021 UK Royal College of Physicians report. ${ }^{66}$ Smoke-free workplaces and bars are also likely to encourage smoke-free homes and change smokers' behaviours in relation to exposing other people and family to SHS. There is also evidence that increasing smoke-free spaces (and the consequent reduction in opportunities to smoke) can be an important stepping-stone or driver to smoking cessation efforts. ${ }^{6768}$ Lastly, it is a common misconception that smoke-free laws only protect non-smokers. They do, of course, also protect smokers from SHS: an interesting finding from the evaluation of Scotland's smoke-free laws was that smokers saw a reduction in cardiovascular events comparable with that experienced by non-smokers. SHS harms and kills smokers too. ${ }^{69}$

\section{Policies are not just about laws}

There is a danger of assuming that smoke-free policies are just about legislation and formal laws to restrict smoking within specific settings, and certainly much of the WHO analysis of national progress focuses on the existence or adoption of legal measures. Smoke-free policies also include guidance and encouragement to implement voluntary smoking restrictions in settings where regulation by law is not appropriate or expectations of privacy would render enforcement impossible. One example of policy in relation to protecting children from SHS comes from the Scottish government's example of implementing a national target of reducing the proportion of children exposed to SHS at home by 50\% between 2012 and $2020 .^{70}$ This policy measure helped drive a government-backed mass-media campaign around the benefits of parents protecting their child from SHS and practical steps that could help households become smoke-free spaces. Smoke-free policies in the workplace can also help influence behaviour: data from Malaysia show that people employed in smoke-free workplaces are about two times more likely to implement a smoke-free home. ${ }^{71}$

\section{Where are we now?}

The extent of benefits from smoke-free policies is difficult to disentangle from other tobacco control measures particularly given the indirect effects of smoke-free measures on cessation and reduced uptake. The American Cancer Society Cancer Action Network has provided state-by-state estimates of lives and financial benefits of smoke-free laws in the USA, ${ }^{72}$ while historical literature is also available detailing the burden of exposure to SHS that can be used to gauge potential benefits of smoke-free regulation. ${ }^{73}$ Given that SHS exposure is still estimated to lead to the premature deaths of 800000 people and that approximately one-quarter of the world's population on non-smokers continue to be exposed, the health and economic costs of global failure to implement smoke-free environments are clearly substantial.

Figure 2 shows the number of annual publications using the term 'smoke-free' across all journals listed in the PubMed database between 1976 and 2020. There is a clear increase in scientific activity on this topic during this time, with sustained growth between 2000 and 2015. It is worth noting however that numbers of publications on this topic have now levelled and show signs of falling in recent years. There is a danger that the tobacco control community begin to think that SHS exposure is a 'thing of the past' and that smoke-free measures have achieved the desired aim of protecting non-smokers around the world. Data showing reductions of $97 \%$ in population-level non-smokers' salivary cotinine concentrations over the past 20 years in countries with comprehensive smoke-free laws and high levels of compliance ${ }^{74}$ should be recognised as success stories, but should not stand in the way of encouraging new thinking and new policies required globally.

The extent to which smoke-free policies should also apply to e-cigarettes and HTPs is something that is increasingly under 


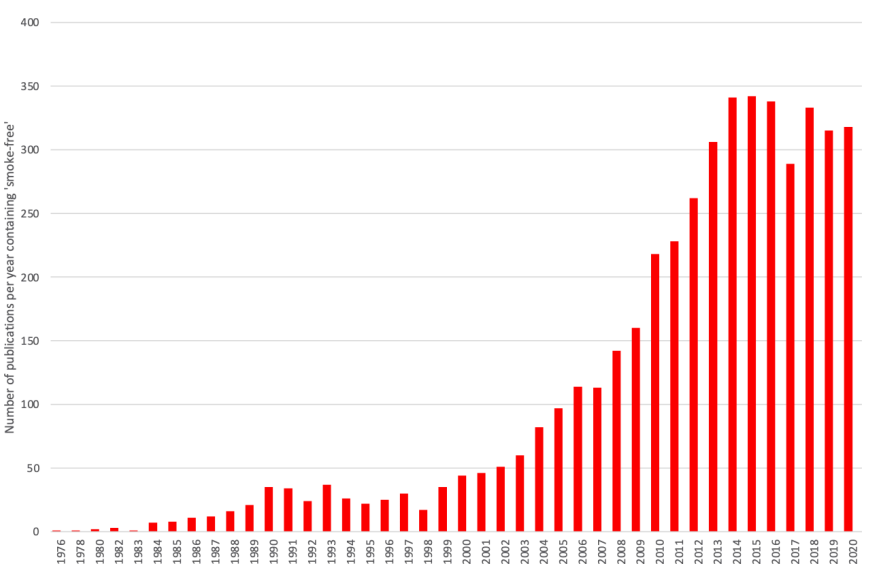

Figure 2 Scientific publications in PubMed containing the term 'smoke-free' between 1976 and 2020.

scrutiny. $^{21}$ Data from Japan ${ }^{75}$ suggest that workplace policies that permit the use of e-cigarettes and HTPs may be associated with increased levels of smoking normalisation.

\section{The tobacco industry: a threat to smoke-free policies}

Ever since Hirayama first demonstrated the link between living with a smoker and lung cancer, ${ }^{76}$ the tobacco industry has orchestrated efforts to obscure, deny and downplay the harm caused by SHS. ${ }^{77} 78$ These efforts have included campaigns against smoke-free public places' policies, including efforts to persuade the hospitality industry to stop smoke-free bars, restaurants and pubs. ${ }^{79}$ While these efforts have largely been defeated in high-income countries, sustained opposition may continue to frustrate campaigners and legislators in LMICs, where governments can ill-afford industry lawsuits. In Uganda, implementation of smoke-free legislation was alleged to be complicated by tobacco industry 'misinformation', with relationships between the industry and the government singled out as a matter of concern. ${ }^{80}$ In 2020, Matthes and colleagues ${ }^{81}$ identified needs for better access to information, policymakers and the media as crucial in interviews with tobacco control advocates in LMICs, and highlighted risks associated with tobacco industry access to policymakers (in contravention of FCTC Article 5.3). ${ }^{14}$

Tobacco industry tactics continue to evolve in response to regulation, circumstance and public opinion. ${ }^{82}$ Newer industry efforts may include the promotion of e-cigarettes or HTPs as alternatives to smoking, framing e-cigarettes and HTPs as fundamentally different from combustible tobacco in attempts to avoid regulation and persuade the public that the industry shares the goal of helping people quit. ${ }^{83}$

Even the term 'smoke-free' is not safe from industry interference. The Philip Morris International-funded 'Foundation for a Smoke-Free World' claims to support tobacco harm reduction measures with an eventual goal of a world without combustible tobacco. But the foundation's independence from its parent company has been questioned ${ }^{84}$ and its efforts have been widely rejected by tobacco control researchers and advocates, who have largely refused its funding. ${ }^{85}$

\section{THE FUTURE}

There is a tendency to focus on smoking cessation and preventing uptake as the most direct pathway to tackling the harms of tobacco, but it is important to remember the benefits that smoke-free policies can play both in assisting cessation and prevention of uptake, and in tackling the immediate and urgent need to protect everyone from the harmful effects of SHS. As we move towards a tobacco endgame, smoke-free environments can also play a fundamental role in the denormalisation of smoking across society.

Support for smoke-free measures is strong in many countries and communities. There is a need for policymakers to be bold and to push for measures that realise the potential benefits of extending smoke-free policies-both formal legislation and public health guidance-beyond the 'enclosed public space' approach of the past two decades. Policies that seek to restrict smoking in outdoor settings and protect people within private spaces including the home will be key to addressing the tobacco epidemic. Governments and the WHO should look at measuring the proportion of people who are protected from SHS exposure across all parts of their daily life and not just within workplace or public space environments, and setting national targets to reduce, year on year, the number of children and adult non-smokers who have measurable levels of salivary cotinine as ascertained by a standard methodology with identical limits of detection.

There are important questions around the limits that society wants to place on e-cigarette use at work, leisure, outdoor and home settings and whether vape-free policies should be applied where smoke-free measures are implemented. The benefits and drawbacks of e-cigarettes are complex ${ }^{86}$ and aligning vape-free spaces with smoke-free measures requires further research. Use of e-cigarettes at home is undoubtedly less harmful when compared with smoking traditional cigarettes within the home but it is not risk-free to bystanders and those exposed to SHA, and there are concerns that children seeing parents vape will be more likely to mimic the handto-mouth action of using vapes. Similarly, there are concerns that making spaces vape-free could encourage smokers who are trying to quit using e-cigarettes to have to move to outdoor spaces shared with smokers, with the potential for increased relapse in quitting attempts.

Post-COVID-19 there are major challenges to how we shape smoke-free policies particularly around home working and protecting people from SHS and SHA in spaces that become a mix of private living and shared work space at different stages of the day. Education and empowerment, together with government-led guidance and policies to produce cultural changes around protecting our families, colleagues and communities from exposure to smoke, will be key in this journey. The potential for gains to global public health is large. The 'P' task in MPOWER has never been more important for more people, and the tobacco control community has a job to do in the next decade. We should not lose sight of the importance of 'smoke-free'.

\section{What this paper adds}

Smoke-free policies cover an increasing proportion of global population.

- Policies tend to focus on enclosed public and workspaces but tend not to tackle home and car settings.

- Children are being left behind in terms of protection from secondhand smoke: with adults benefiting proportionately more than children from smoke-free policies.

- Governments and the WHO should set objective targets to reduce the proportion of children exposed to secondhand smoke.

Twitter Rachel O’Donnell @RachelODonnell and Esteve Fernández @stvfdz 
Contributors This was an invited manuscript. SS generated the first draft and all authors then contributed to the editing and refining of this to produce the final version.

Funding This work was carried out as part of employment at the University of Stirling (SS, RD and RO'D), Universiti Putra Malaysia (EZA), University of Cambridge (GO) and the Catalan Institute of Oncology-ICO (OT and EF). This manuscript was invited by the editor and was externally peer reviewed.

Competing interests None declared.

Patient consent for publication Not required.

Provenance and peer review Commissioned; externally peer reviewed.

\section{ORCID iDs}

Sean Semple http://orcid.org/0000-0002-0462-7295

Esteve Fernández http://orcid.org/0000-0003-4239-723X

\section{REFERENCES}

1 Xiao $\mathrm{H}$, Zhang $\mathrm{H}$, Wang $\mathrm{D}$, et al. Impact of smoke-free legislation on acute myocardial infarction and stroke mortality: Tianjin, China, 2007-2015. Tob Control 2020;29:61-7.

2 Lee SL, Wong WHS, Lau YL. Smoke-Free legislation reduces hospital admissions for childhood lower respiratory tract infection. Tob Control 2016;25:e90-4.

3 López CMG, Ruiz JAJ, Shigematsu LMR, et al. The economic impact of Mexico City's smoke-free law. Tob Control 2011;20:273-8.

4 Macy JT, Hernandez EL. The impact of a local smoke-free air law on wagering at an off-track betting facility in Indiana. Tob Control 2011;20:383-4.

5 Williams SC, Hafner JM, Morton DJ, et al. The adoption of smoke-free Hospital campuses in the United States. Tob Control 2009;18:451-8.

6 Snyder K, Vick JH, King BA. Smoke-Free multiunit housing: a review of the scientific literature. Tob Control 2016;25:9-20.

7 Wilson N, Jones AC, Thomson GW. Poor smoke-free status of airports in a country with a smoke-free goal: new Zealand. Tob Control 2021;30:704

8 Cambodia: smoke-free pagoda. Tob Control 2000;9:268

9 Johns M, Farley SM, Rajulu DT, et al. Smoke-Free Parks and beaches: an interrupted time-series study of behavioural impact in New York City. Tob Control 2015;24:497-500.

10 Woodward A, Laugesen M. How many deaths are caused by second hand cigarette smoke? Tob Control 2001;10:383-8.

11 Hawsawi AM, Bryant LO, Goodfellow LT. Association between exposure to secondhand smoke during pregnancy and low birthweight: a narrative review. Respir Care 2015;60:135-40.

12 Merghani TH, Saeed AM. The relationship between regular second-hand smoke exposure at home and indictors of lung function in healthy school boys in Khartoum. Tob Control 2013;22:315-8.

13 Hollenbach JP, Schifano ED, Hammel C, et al. Exposure to secondhand smoke and asthma severity among children in Connecticut. PLoS One 2017;12:e0174541.

14 World Health Organisation. Framework convention on tobacco control, 2003. Available: https://fctc.who.int/who-fctc/overview [Accessed 3rd June 2021].

15 World Health Organisation. Tobacco free initiative. MPOWER brochures and other resources, 2009. Available: https://www.who.int/tobacco/mpower/publications/en/ [Accessed 3rd June 2021].

16 Semple S, Ibrahim AE, Apsley A, et al. Using a new, low-cost air quality sensor to quantify second-hand smoke (shs) levels in homes. Tob Control 2015;24:153-8.

17 López MJ, Nebot M, Schiaffino A, et al. Two-year impact of the Spanish smoking law on exposure to secondhand smoke: evidence of the failure of the 'Spanish model'. Tob Control 2012;21:407-11.

18 Jones IA, St Helen G, Meyers MJ, et al. Biomarkers of secondhand smoke exposure in automobiles. Tob Control 2014:23:51-7.

19 Yang XY, Yang T, Nie F. Air pollution as a catalyst for supporting tobacco control policies? Evidence from a nationwide study on Chinese medical students. Tob Control 2018;27:505-12.

20 Zhou S, Weitzman M, Vilcassim R, et al. Air quality in New York City hookah bars. Tob Control 2015;24:e193-8.

21 Amalia B, Fu M, Feliu A, et al. Regulation of electronic cigarette use in public and private areas in 48 countries within the who European region: a survey to in-country informants. J Epidemiol 2020. doi:10.2188/jea.JE20200332. [Epub ahead of print: 19 Dec 2020].

22 Amalia B, Liu X, Lugo A, et al. Exposure to secondhand aerosol of electronic cigarettes in indoor settings in 12 European countries: data from the TackSHS survey. Tob Control 2021;30:49-56.

23 Ballbè M, Martínez-Sánchez JM, Sureda X, et al. Cigarettes vs. e-cigarettes: passive exposure at home measured by means of airborne marker and biomarkers. Environ Res 2014;135:76-80.

24 Brown R, Van Godwin J, Page N, et al. Implementation of e-cigarette regulation through the EU tobacco products directive (2016) in Wales, Scotland and England from the perspectives of stakeholders involved in policy introduction and enforcement. Tob Prev Cessat 2021;7:36
25 Bhalerao A, Sivandzade F, Archie SR, et al. Public health policies on e-cigarettes. Curr Cardiol Rep 2019;21:111.

26 GBD 2019 Tobacco Collaborators. Spatial, temporal, and demographic patterns in prevalence of smoking tobacco use and attributable disease burden in 204 countries and territories, 1990-2019: a systematic analysis from the global burden of disease study 2019. Lancet 20212021;397:01169-7.

27 GBD. Risk factors Collaborators. global, regional, and national comparative risk assessment of 84 behavioural, environmental and occupational, and metabolic risks or clusters of risks, 1990-2016: a systematic analysis for the global burden of disease study 2016. Lancet 20162017:390:1345-422.

28 et alDrope J, Schluger N, Cahn Z. The tobacco atlas. Atlanta: American cancer Society and vital strategies, 2018. Available: https://tobaccoatlas.org/topic/secondhand/ [Accessed 3rd June 2021].

29 Mbulo L, Palipudi KM, Andes L, et al. Secondhand smoke exposure at home among one billion children in 21 countries: findings from the global adult tobacco survey (GATS). Tob Control 2016;25:e95-100.

30 Hajizadeh M, Nandi A. The socioeconomic gradient of secondhand smoke exposure in children: evidence from 26 low-income and middle-income countries. Tob Control 2016;25:e146-55.

31 Hyland A, Barnoya J, Corral JE. Smoke-Free air policies: past, present and future. Tob Control 2012;21:154-61.

32 Office on Smoking and Health (US). The health consequences of involuntary smoking: a report of the surgeon General. Rockville, Maryland: Public Health Service, 1986.

33 Office on Smoking and Health (US). The health consequences of involuntary exposure to tobacco smoke: a report of the surgeon General. Atlanta (GA): centers for disease control and prevention (US, 2006. https://www.ncbi.nlm.nih.gov/books/NBK44324/

34 Weber MD, Bagwell DAS, Fielding JE, et al. Long term compliance with California's smoke-free workplace law among bars and restaurants in Los Angeles County. Tob Control 2003;12:269-73.

35 Jones MR, Barnoya J, Stranges S, et al. Cardiovascular events following smoke-free legislations: an updated systematic review and meta-analysis. Curr Environ Health Rep 2014;1:239-49.

36 Mackay DF, Pell JP. Ten-Year follow-up of the impact of Scottish smoke-free legislation on acute myocardial infarction. Circ Cardiovasc Qual Outcomes 2019;12:e005392.

37 World Health Organisation. Who report on the global tobacco epidemic 2021: addressing new and emerging products. Available: https://www.who.int/publications/ i/item/9789240032095 [Accessed 29th October 2021].

38 Bosdries J, Willemsen M, Stronks K. Tobacco control policy development in the European Union: do political factors matter? Eur J Public Health 2015;25:90-194.

39 Feliu A, Filippidis FT, Joossens L, et al. The association between tobacco control policy implementation and country-level socioeconomic factors in 31 European countries. Sci Rep 2021;11:8912.

40 World Health Organisation. Who report on the global tobacco epidemic 2019: offer help to quit tobacco use. Annex VI: table 6.1 - public places with smoke-free legislation. Available: https://www.who.int/teams/health-promotion/tobaccocontrol/who-report-on-the-global-tobacco-epidemic-2019 [Accessed 29th October 2021].

41 Barnoya J, Monzon JC, Briz P, et al. Compliance to the smoke-free law in Guatemala 5-years after implementation. BMC Public Health 2016;16:318.

42 Ferketich AK, Lugo A, La Vecchia C, et al. Relation between national-level tobacco control policies and individual-level voluntary home smoking bans in Europe. Tob Control 2016:25:60-5

43 Feliu A, Filippidis FT, Joossens L, et al. Impact of tobacco control policies on smoking prevalence and quit ratios in 27 European Union countries from 2006 to 2014. Tob Control 2019:28:101-9.

44 Gravely S, Nyamurungi KN, Kabwama SN, et al. Knowledge, opinions and compliance related to the $100 \%$ smoke-free law in hospitality venues in Kampala, Uganda: crosssectional results from the KOMPLY Project. BMJ Open 2018;8:e017601.

45 Sureda X, Fernández E, López MJ, et al. Secondhand tobacco smoke exposure in open and semi-open settings: a systematic review. Environ Health Perspect 2013;121:766-73.

46 Tobacco Control Laws. Available: https://www.tobaccocontrollaws.org/ [Accessed 8thOctober 2021].

47 Peruga A, Molina X, Delgado I, et al. Compliance with the smoking ban in enclosed, semiopen and open areas of workplaces and public places in Chile. Tob Control 2021:30:570-3.

48 Henderson $E$, Continente $X$, Fernández E, et al. Secondhand smoke exposure assessment in outdoor hospitality venues across 11 European countries. Environ Res 2021;200:111355.

49 Semple S, Apsley A, Azmina Ibrahim T, et al. Fine particulate matter concentrations in smoking households: just how much secondhand smoke do you breathe in if you live with a smoker who smokes indoors? Tob Control 2015;24:e205-11.

50 Semple S, Turner S, O'Donnell R, et al. Using air-quality feedback to encourage disadvantaged parents to create a smoke-free home: results from a randomised controlled trial. Environ Int 2018:120:104-10.

51 American Nonsmokers' Rights Foundation. Smoke-free multiunit housing policies: where are we now? 2021. Available: https://no-smoke.org/smokefree-multi-unithousing-policies-now 
52 Semple S, Apsley A, Galea KS, et al. Secondhand smoke in cars: assessing children's potential exposure during typical journey conditions. Tob Control 2012;21:578-83.

53 Laverty AA, Filippidis FT, Been JV, et al. Smoke-free vehicles - impact of legislation on child smoke exposure across three countries. Eur Respir J 2021. doi:10.1183/13993003.04600-2020. [Epub ahead of print: 24 Sep 2021].

54 Sureda X, Fernández E, Martínez-Sánchez JM, et al. Secondhand smoke in outdoor settings: smokers' consumption, non-smokers' perceptions, and attitudes towards smoke-free legislation in Spain. BMJ Open 2015;5:e007554.

55 Schick SF, Schick S. Thirdhand smoke: here to stay. Tob Control 2011;2022:1428-3.

56 Demou E, Dobson R, Sweeting $H$, et al. From smoking-permitted to smokefree prisons: a 3-year evaluation of the changes in occupational exposure to second-hand smoke across a national prison system. Ann Work Expo Health 2020;64:959-69.

57 Holmes LM, Ling PM. Workplace secondhand smoke exposure: a lingering hazard for young adults in California. Tob Control 2017;26:e79-84.

58 Dobson R, Demou E, Semple S. Occupational exposure to second-hand tobacco smoke: development of a job exposure matrix. Ann Work Expo Health 2021 doi:10.1093/annweh/wxab019. [Epub ahead of print: 03 Apr 2021].

59 Osinibi M, Gupta A, Harman K. Passive tobacco smoke in children and young people during the COVID-19 pandemic. Lancet Respir Med 2021;S2213-2600:00231-9.

60 O'Donnell R, Eadie D, Stead M, et al. 'I was smoking a lot more during lockdown because I can': a qualitative study of how UK smokers responded to the Covid-19 lockdown. Int J Environ Res Public Health 2021;18:5816.

61 Wilson KM, Klein JD, Blumkin AK, et al. Tobacco-smoke exposure in children who live in multiunit housing. Pediatrics 2011;127:85-92.

62 Rydz E, Arrandale VH, Peters CE. Population-level estimates of workplace exposure to secondhand smoke in Canada. Can J Public Health 2020;111:125-33.

63 Belvin C, Britton J, Holmes J, et al. Parental smoking and child poverty in the UK: an analysis of national survey data. BMC Public Health 2015;15:507.

64 Clawson AH, McQuaid EL, Dunsiger S, et al. The longitudinal, bidirectional relationships between parent reports of child secondhand smoke exposure and child smoking trajectories. J Behav Med 2018;41:221-31.

65 Henderson E, Continente X, Fernández E, et al. Secondhand smoke exposure in outdoor children's playgrounds in 11 European countries. Environ Int 2021:149:105775

66 Royal College of Physicians. Smoking and health 2021: a coming of age for tobacco control? London: RCP, 2021. Available: https://www.rcplondon.ac.uk/projects/outputs/ smoking-and-health-2021-coming-age-tobacco-control [Accessed 3rd June 2021].

67 Titus AR, Kalousova L, Meza R, et al. Smoke-free policies and smoking cessation in the United States, 2003-2015. Int J Environ Res Public Health 2019;16:3200.

68 Haardörfer R, Kreuter M, Berg CJ, et al. Cessation and reduction in smoking behavior: impact of creating a smoke-free home on smokers. Health Educ Res 2018;33:256-9.

69 Pell JP, Haw S, Cobbe S, et al. Smoke-free legislation and hospitalizations for acute coronary syndrome. N Engl J Med 2008;359:482-91.

70 Scottish Government. Raising Scotland's tobacco-free generation: our tobacco control action plan 2018, 2018. Available: https://www.gov.scot/publications/raising- scotlands-tobacco-free-generation-tobacco-control-action-plan-2018/ [Accessed 3rd June 2021].

$71 \mathrm{Lim} \mathrm{KH}$, Lim HL, Teh CH, et al. Is the implementation of smoke-free policies at workplaces associated with living in a smoke-free home?: findings from a national population-based study in Malaysia. Tob Induc Dis 2019;17:51.

72 American Cancer Society Cancer Action Network. Saving lives, saving money. A state-by-state report on the health and economic impact of comprehensive smokefree laws, 2011. Available: https://www.fightcancer.org/sites/default/files/National\% 20Documents/acscan-smoke-free-laws-report.pdf [Accessed 3rd June 2021].

73 Jamrozik K. Estimate of deaths attributable to passive smoking among UK adults: database analysis. BMJ 2005;330:812.

74 Semple S, Mueller W, Leyland AH, et al. Assessing progress in protecting non-smokers from secondhand smoke. Tob Control 2019;28:692-5.

75 Siripongvutikorn Y, Tabuchi T, Okawa S. Workplace smoke-free policies that allow heated tobacco products and electronic cigarettes use are associated with use of both these products and conventional tobacco smoking: the 2018 JASTIS study. Tob Control 2021;30:147-54.

76 Hirayama T. Non-Smoking wives of heavy smokers have a higher risk of lung cancer: a study from Japan. Br Med J (Clin Res Ed) 1981;282(6259:183-5.

77 Tong EK, Glantz SA. Tobacco industry efforts undermining evidence linking secondhand smoke with cardiovascular disease. Circulation 2007;116:1845-54.

78 Tong EK, England L, Glantz SA. Changing conclusions on secondhand smoke in a sudden infant death syndrome review funded by the tobacco industry. Pediatrics 2005;115:e356-66.

79 Dearlove JV, Bialous SA, Glantz SA. Tobacco industry manipulation of the hospitality industry to maintain smoking in public places. Tob Control 2002;11:94-104.

80 Robertson L, Nyamurungi KN, Gravely S, et al. Implementation of 100\% smoke-free law in Uganda: a qualitative study exploring civil society's perspective. BMC Public Health 2018;18:927.

81 Matthes BK, Robertson L, Gilmore AB. Needs of LMIC-based tobacco control advocates to counter tobacco industry policy interference: insights from semistructured interviews. BMJ Open 2020;10:e044710.

82 Assunta M, Dorotheo EU. SEATCA tobacco industry interference index: a tool for measuring implementation of who framework convention on tobacco control article 5.3. Tob Control 2016:25:313-8

83 Rosen LJ, Kislev S. IQOS campaign in Israel. Tob Control 2018;27:s78-81.

84 van der Eijk Y, Bero LA, Malone RE. Philip morris international-funded 'foundation for a smoke-free world': analysing its claims of independence. Tob Control 2019;28:712-8

85 Legg T, Peeters S, Chamberlain P, et al. The philip morris-funded foundation for a smoke-free world: tax return sheds light on funding activities. Lancet 2019;393:2487-8

86 National Academies of Sciences Engineering and Medicine. Public health consequences of e-cigarettes. conclusions by outcome. 2018. Available: https://www. nap.edu/resource/24952/012318ecigaretteConclusionsbyOutcome.pdf [Accessed 8th Oct 2021]. 